\title{
Group Creativity in Learning Context: Understanding in a Social-Cultural Framework and Methodology
}

\author{
Chunfang Zhou ${ }^{1}$, Lingling Luo ${ }^{2}$ \\ ${ }^{1}$ Department of Development and Planning, Aalborg University, Aalborg, Denmark \\ ${ }^{2}$ Research Center for Science, Technology and Society, School of Humanities and Law, Northeastern University, \\ Shenyang, China \\ Email: chunfang@plan.aau.dk, lll_19500619@126.com
}

Received June 28 ${ }^{\text {th }}, 2012$; revised July 30 ${ }^{\text {th }}$, 2012; accepted August $10^{\text {th }}, 2012$

\begin{abstract}
Recent studies have emphasized group creativity as a social-cultural conception, but they lack a focus on the relationship between group creativity and knowledge creation. This paper aims to build a framework for group creativity in a learning context which includes both theoretical understanding and empirical methodology. Thus, a literature review is led by the following questions: How has creativity theory been developed from individual to group level? From a social-cultural perspective, how can group creativity, knowledge creation, and their relationship be understood? And what methods have been employed to study group creativity? As the review demonstrates, creativity theory has been driven by new insights from recent sociology studies. Three focuses have been shaped from group creativity studies: 1) group creativity in context; 2) group-level creative synergy; and 3) strategies for developing group creativity. Individual knowledge is a potential resource for group creativity, and group creativity could be a driver of knowledge creation. Empirically, group creativity can be examined through both qualitative and quantitative approaches, which also calls for a creative combination of methodologies in future studies.
\end{abstract}

Keywords: Group Creativity; Knowledge Creation; Leaning Context; Methodology

\section{Introduction}

Recently, the concept of creativity has gained importance. A sign of the importance of creativity is the decision of the European Union to make 2009 the European Year of Creativity and Innovation. The objective of the year is to promote creativity for all as a driver for innovation and as a key factor for the development of personal, occupational, entrepreneurial and social competences through lifelong learning (European Commission, 2008). The year should raise public awareness and promote public debate on creativity; it also should stimulate research into how to develop creativity and innovative attitudes (Villalba, 2008). Accordingly, a vast amount of management literature has been increasingly focusing on how to enhance creativity in the workplace, in order to cope with a constantly changing environment (Borghini, 2005). For education systems, promoting creativity has been suggested as one of the priorities for meeting the challenges of the twenty-first century (Craft, Jeffery, \& Leibling, 2001).

Generally, creativity is the ability to produce work that is both novel (i.e., original, unexpected) and appropriate (i.e., useful, adaptive when it comes to task constraints) (Sternberg \& Lubart, 1999). However, most creative acts occur in a collaborative context (Sonnenburg, 2004). For example, groups provide a sufficient pool of knowledge, experiences, and views to produce an optimal outcome at each stage of the problemsolving process (Lohman \& Finkelstein, 2000). Therefore, the collaborative or social aspect of creativity is stressed and group creativity has been focused on in studies (Paulus, 2003). Littleton and his colleagues (2008) emphasized that, whilst research on creativity has frequently stressed the role of the individual as producer, contemporary work has afforded a characterization of the creative processes as dynamic, fundamentally social, and necessarily collective and collaborative. Similarly, contemporary literature on learning theory has suggested a move away from an individualistic conception of learning, locating it within a wider social-cultural context. Increasingly, knowledge is believed to be constructed in settings of joint activity, where people are dedicated to learn and collaborate around shared tasks and issues that matter to them (De Laat \& Lally, 2004).

Thus, the previous work indicates the need for a knowledgecreation view of group creativity in a learning context. Although there are discussions on learning and creativity in previous work, for example, the concept of "mini c" (Beghetto \& Kaufman, 2007) emphasizes the creative process involved in the construction of personal knowledge and understanding, and Amabile (1996) emphasizes that creativity does not occur spontaneously or randomly, but happens when the appropriate combinations of knowledge, skills, and motivation enable an individual to create new ideas, there is lack of a clear framework for theoretical understanding and empirical studies on group creativity. These points lead this paper to review published studies in order to answer the following questions:

1) How has creativity theory been developed from individual to group level?

2) From a social-cultural perspective, how can group creativity, knowledge creation, and their relationship be understood?

3) What methods have been employed to study group creativity?

The above questions help to structure this paper and lead to a proposed framework for use as a guideline for understanding a knowledge-creation view of group creativity as well as empiri- 
cal methodologies for future study. Thus, this paper contributes to the development of group creativity in education, both theoretically and empirically. In addition, it also has implications for educators about how to build a learning environment conducive to creativity, and how to make better use of group learning methods for creativity development.

\section{Creativity Theory: From Individual Level to Group Level}

The early stages of creativity research focused on the psychological determinants for the individual of genius and giftedness (Jeffrey \& Craft, 2001). As Kurtzberg and Amabile (2000-2001) describe, J. P. Guilford's 1950 address to the American Psychological Association inspired the thriving new field of creativity research. Guilford argued that creativity is a continuous trait in all people, and that those individuals with recognized creative talent simply have "more of what all of us have” (Guilford, 1950). As with any founding contribution, Guilford's choice of focus on the traits, motivations, and behaviors of the creative individual shaped the way that creativity has been conceptualized in the decades since (Kurtzberg \& Amabile, 2000-2001).

Research into creativity in the 1980s and 1990s became rooted in a social-psychological framework in which it was recognized that social structures affect individual creativity (Jeffrey \& Craft, 2001). According to Rhyammar and Brolin (1999), there were major lines of development from the 1950s focusing on personality, cognition, and how to stimulate creativity. This was supported by the philosophical debate from the 1970s which saw creativity moving away from product outcomes and becoming connected with imaginativeness. During the 1980s, a new line was developed, that of social psychology and systems theory, where environmental conditions were taken into account. Within these four lines of development (i.e., personality, cognition, stimulating creativity, and social theories) there were the following specific focuses: the person who creates, the creative process, environmental factors, and the outcome. During the 1990s, due to the development of the fourth line-social psychology—research into creativity became more comprehensive, integrating these specific focuses, and it began to focus more on the creativity of ordinary people within the education system (Jeffrey \& Craft, 2001). Accordingly, Sternberg (1999) points out that the development of scientific thinking about creativity has followed a particular trajectory: going from an early emphasis upon isolated individuals and their internal traits and capabilities, to developing a focus on the interaction between individuals and the environment.

It has been asserted that a theoretical model, which is useful for management studies, should study creativity from a multilevel perspective and consider at least three levels of analysis: 1) intrasubjective (individual); 2) intersubjective (group); and 3) collective (organization). This approach allows us to understand how in the creative process, individuals (in the context of groups and organizations) contribute to the outcome of a creative product through a sensemaking process (Borghini, 2005). Group creativity is a function of individual creative behavior "inputs", the interaction of the individuals involved (e.g., group composition), group characteristics (e.g., norms, size, degree of cohesiveness), group processes (e.g., approaches to problem solving), and contextual influences (e.g., the larger organization, characteristics of group task). The interaction between individ- ual, group, and organizational creativity has been emphasized (Woodman, Sawyer, \& Criffin, 1993), and group creativity has been specifically discussed by researchers such as Paulus and Nijstad (2003), Sawyer (2007), Robinson and Stern (1997), Leonard-Barton and Swap (1999), and Miell and Littleton (2004). The published studies indicate three main focuses:

1) Group creativity in context: this means taking the shaping roles of specific external social environments into account. Groups are not a closed system but interact with their environment. Whether a group will achieve its creative potential mainly depends on the (social) context. The context, consisting of the task the group performs, the group climate, group norms, the larger organizational climate, and so on, drives group processes. For example, an open climate has been emphasizedgroups need to be open and safe and group members should feel free to offer "crazy" ideas; at the same time, there should be room for debate and constructive controversy (Nijstad \& Paulus, 2003). Furthermore, the organizational or even national or cultural environment of a group can affect group creativity. As Paulus and Nijstad (2003) suggested, in organizations in which creativity and innovation are not valued, group creativity will be severely constrained. Further, a restrictive cultural climate, such as a conservative religious government, may have similar effects to those of a restrictive group climate.

2) Group-level creative synergy: this means taking the collaborative relationships in groups into account. As Moran and John-Steiner (2004) suggested, collaboration has been of considerable interest to research because it extends our understanding of creativity beyond the individual. Interest in collaboration rests, implicitly or explicitly, on the assumption that human cognition is an interpersonal as well as an intrapersonal process (Levine \& Moreland, 2004). It involves an intricate blending of skills, temperaments, effort and sometimes personalities to realize a shared vision of something new and useful (Moran \& John-Steiner, 2004). So one could therefore argue that groups have creative potential; since individual knowledge, skills, and abilities are combined, the group has the potential to be more creative together than its members have separately. However, for groups to be creative, the group process must be structured in a way that prevents process loss (Nijstad \& Paulus, 2003), so factors such as individual motivation (Cooper \& Jayatilaka, 2006), group diversity, and conflict have been emphasized in group creativity development (Kurtzberg \& Amabile, 2000-2001).

3) Strategies for developing group creativity: this means taking strategies of enhancing creative group work (for example, building an creative organizational or educational environment or using creativity techniques) into account. As Paulus (2000) suggested, innovation will be high when organizations provide rewards, some discretion in job activities, and supportive leadership, and when groups have a clear vision or goal, norms that support innovation, an atmosphere in which it is safe to express novel ideas, and a commitment to task excellence. So Thompson and Brajkovich (2003) discuss four threats to group creativity: social loafing, conformity, production blocking, and downward norm setting. Ten strategies are suggested for enhancing creativity and for making it part of the creative team's culture: a) diversifying the team; b) analogical reasoning; c) brainwriting; d) nominal group techniques; e) creating organizational memory; f) trained facilitators; g) high benchmarks; h) membership change; i) electronic brainstorming; and j) creating a playground. Creativity techniques have also emphasized, for 
example, group brainstorming (Paulus, 2003) and creative problem-solving approaches (Woodman, Sawyer, \& Griffin, 1993).

In addition, Nijstad and Paulus (2003) have summarized four common themes in recent studies of group creativity: 1) group diversity and creative potential; 2) obstacles to the realization of creative potential; 3) group climate; and 4) group environment. The four themes, as well as many other issues that have received attention, contribute to building a framework that has some potential to facilitate further studies. Nijstad and Paulus (2003) also come up with questions about future directions: What are the relevant inputs group members bring to their task? Under what conditions are individual inputs contributed in an optimal way? How are individual contributions combined to yield a creative group response? Under what conditions does group creativity affect the environment of the group? Furthermore, "knowledge-creating" has been recently defined as the main characteristic of a company (Nonaka, 1991). Organizations are viewed as innovative knowledge communities (Paavola, Lipponen, \& Hakkarainen, 2004) because creativity and innovation concern the process of creating and applying new knowledge (Livingstone \& Lynch, 2000). This calls for a link to be made between group creativity and learning by considering knowledge creation from a social-cultural perspective.

\section{A Social-Cultural Perspective of Learning, Group Creativity, and Knowledge Creation}

\section{What a Social-Cultural Perspective Implies for Learning}

According to Aschenbrenner and Hellwig (2009), as the name implies, two words are central to the social-cultural approach to educational issues: "social" and "cultural". When something is social, it is automatically interconnected and has reference to other people. Weber (1922) defined "social acting" in a way that the sense of the action is related to others' behavior. An example can be shown here:

If I found a wallet lying on the street, I would bring it to the lost property office in anticipation of someone who's searching for it. If I weren't expecting that, it wouldn't be a kind of social behavior. So the relation to others' behavior gives sense to my acting and initiates it, consequently it is social acting. Moreover, the sequence of a social action is oriented to others. The social commitment, how to drink beer in a community, hence you clink glasses and have a sip of your drink, structures the procedure and gives sense to it. You see, social acting is an essential part of our everyday life and also occurs at the workplace (Aschenbrenner \& Hellwig, 2009).

The meaning of the second word "culture" is a classical anthropological issue (Aschenbrenner \& Hellwig, 2009). As Sawyer (2006) points out, anthropologists use the word "culture" in a way that is related to common contemporary phrases like "popular culture”, "mass culture”, and "subculture." But it is a little more complex than that, and one of the first definitions in the late nineteenth century was that of Edward Tylor (1889), who thought culture is the complex whole which includes knowledge, belief, art, law, morals, customs, and any other capabilities and habits acquired by a person as a member of society. Goodenough (cited in Cole, 2005) described culture as something, which "one needs to know to participate acceptabtly as a member in a society's affairs” (p. 265); whilst Aschenbrenner and Hellwig (2009) pointed out that culture is the in- terconnection between individuals and objects in the environment through their usage in a specific and socially legitimate way. Moreover, culture is necessary to participate in the social environment. Because of that, culture is both a contextual and a cognitive phenomenon: the context influences and creates human cognitive structures and vice versa.

The social-cultural perspective on learning was first systematized and applied by Vygotsky and his collaborators in Russia in the nineteen-twenties and thirties (Corsi et al., 2006). According to this perspective, intellectual development is achieved through dialogue and education is enacted through the interaction between students and teachers, reflecting the historical development, cultural values, and social practices of societies and communities in which educational institutions exist (RojasDrummond, 2008). So knowledge is constructed in settings of joint activity, where people are dedicated to learn and collaborate around shared tasks and issues that matter them (De Laat \& Lally, 2004), and knowledge creation is fundamentally a social process which means that social interaction provides essential cognitive resources for human cognitive accomplishment (Nonaka \& Toyama, 2003). This indicates the difficulty of separating group and individual learning experiences. In practice, it has driven a growing interest in the use of team- or group-based learning in education as illustrated by, for example, the problem-based learning approach (Newman, 2005).

\section{Knowledge Creation as a Social Process}

From a social-cultural perspective, understanding is seen as iterative in nature; that is, it emerges through a series of attempts to explain and understand the processes and mechanisms being investigated. Accordingly, new ideas and innovations emerge between rather than within people. The interaction among different forms of knowledge or between knowledge and other activities is emphasized as a requirement for innovativeness in learning and knowledge creation (Paavola, Lipponen, \& Hakkarainen, 2004). So the explicit and tacit knowledge and their interaction in workplace have been focused on (Smith, 2001) and illustrated by models which are based on concept of "knowledge-creating companies" (Nonaka \& Takeuchi, 1995; Baumard, 1999). Thus, the following sections are organized as 1) explicit knowledge and tacit knowledge; and 2) models of knowledge creation.

1) Explicit knowledge and tacit knowledge. Recently, the concepts of intuitive expertise and tacit knowledge have become increasingly important factors in discussions concerning knowledge and learning in practice. According to Nielsen (2002), there are three main ways of understanding tacit knowledge based on studies such as those of Polanyi (1994), Dreyfus and Dreyfus (1986), and Wagner and Sternberg (1986). Tacit knowledge can be presented as a) embedded in tradition; b) an inexpressible dimension of practice; and c) an aspect of practical intelligence. Accordingly, most literature regards tacit knowledge as more highly personal and harder to communicate or to share with others. It is deeply rooted in an individual's experience, and it consists of schemata, beliefs, and perceptions stored so deep in the worldview of an individual that they are taken for granted (2003). For example, in relation to the context of technology companies, Rosenberg (1982) explains tacit knowledge as: "the knowledge of techniques, methods and designs that work in certain ways and with certain conesquences, even when one cannot explain exactly why” (p. 143). 
Thus, tacit knowledge equates to practical know-how (Koskinen, Pihlanto, \& Vanharanta, 2003).

In contrast, explicit knowledge is the type of knowledge that an individual has acquired mainly at school and university. Explicit knowledge implies factual statements about such matters as material properties, technical information, and tool characteristics. Thus, explicit knowledge can be expressed in words and numbers, and is therefore easily communicated and shared (Koskinen, Pihlanto, \& Vanharanta, 2003). However, knowledge exists on a spectrum. At one extreme it is almost completely tacit, that is, semiconscious and unconscious knowledge held in people's heads and bodies. At the other end of spectrum, knowledge is almost completely explicit, or codified, structured, and accessible to people other than just the individuals originating it. Most knowledge, of course, exists between these extremes. Explicit elements are objective, rational, and created in the "then and there," while the tacit elements are subjective, experiential, and created in the "here and now" (Leonard \& Sensiper, 1998).

Based on this distinction between tacit knowledge and explicit knowledge, studies began to focus on the transformation between the two kinds of knowledge, since the transformation involves learning activities through the engagement of learners. The concept of the "knowledge creating company" (Nonaka, 1991) has been discussed, and related models of knowledge creation have been built, such as Nonaka and Takeuchi's model (1995) and Baumard's model (1999).

2) Models of knowledge creation. As mentioned, most discussions on the transformation between tacit knowledge and explicit knowledge are related to the organizational context (Smith, 2001). Although the distinctions of organizational context and educational context exist, the models of knowledge creation have demonstrated that learning is a dynamic process of dialogue and practice. So they provide a powerful insight into a peer collaborative learning context, and their implications can help educators obtain a better understanding of teaching student groups.

One of the early models was constructed by Nonaka and Takeuchi (1995). This model shows how the two categories of knowledge that form the "knowledge spiral" interact (Figure 1) (Corsi et al., 2006). A knowledge spiral is grounded in four complementary types of knowledge conversation: a) from tacit to tacit knowledge, labeled socialization; b) from tacit to explicit knowledge, called externalization; c) from explicit to explicit knowledge, or combination; and d) from explicit to tacit knowledge, or internalization.

As explained by Paavola et al. (2004), the knowledge creation spiral starts from socialization and sharing tacit knowledge and experiences at the group level. In this phase, close interaction

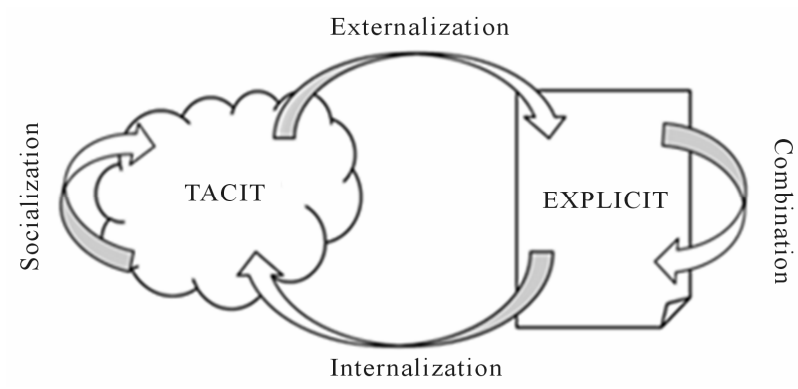

Figure 1.

Nonaka and Takeuchi's model. and collaboration within a group is needed. The aim of the socialization process is to create a common understanding and trust within group. The next phase, externalization, is the central one in knowledge creation. In this phase, tacit knowledge is explicated and conceptualized by means of metaphors, analogies, and concepts. In Nonaka and Takeuchi's model, the basic source of innovation is tacit knowledge, which needs to be explicated in order to be transformed into knowledge that is useful at the levels of the group and the whole organization. At the combination stage, units of already-existing explicit knowledge are combined and exchanged. Finally, to have real effects in an organization, the explicit knowledge of the group or organization must be internalized by individuals and transformed into tacit knowledge and into action through "learning by doing.” After internalization, a new round of the knowledge spiral will begin.

Nonaka and Takeuchi's work has been broadly accepted, especially in the area of organizational management (Corsi et al., 2006). Collaboration can be viewed as a personal philosophy required for group interaction, and cooperation as a (set of) structure(s) facilitating group performance (Strijbos \& Martens, 2001). As pointed out by Paavola et al. (2004), a knowledgecreation approach to learning conceptualizes learning and knowledge advancement as collaborative processes for developing shared objects of activity. Learning is not about conceptualized processes occurring in individuals' minds, or about processes for participation in social practices; instead, learning is understood as a collaborative effort directed toward developing some mediated artifacts, broadly defined as including knowledge ideas, practices, and material or conceptual artifacts. As Corsi et al. (2006) said, we know only at the moment in which we need to know: knowledge is quintessentially contextual and is triggered by circumstances. Therefore, Nonaka and Takeuchi's work has been developed based on the above considerations, and the interaction between individual knowledge and group knowledge has been emphasized by, for example, Baumard's model (Baumard, 1999) (Figure 2).

Recent studies support the claim that a group should be viewed as a learning environment, because apparently specific characteristics of groups affect individual group members, group interaction processes, and group performance (Strijbos \& Martens, 2001). Baumard's model can be used to explain group learning. In Figure 2, the roles of collective knowledge have been emphasized. In diverse groups, the basic resources of groups reside in their members. Members bring knowledge, skills, and abilities to the group, without which the group task cannot be accomplished (Nijstad \& Paulus, 2003). In addition, it is important to note that the four types of knowledge conversation form a spiral, not a circle. In the spiral of knowledge creation, the interaction between tacit knowledge and explicit knowledge and between individual knowledge and group knowledge is dynamic and iterative. The spiral becomes larger in scale when the interactions happen, because the new knowledge is created during the interactions.

A social-cultural perspective, coming from discussion of the two models above, therefore emphasizes ideas developed through collective as well as individual efforts. It is through joint engagement that ideas are argued over, contested, borrowed, and shared as our understanding is advanced. Such understanding is a dialogical phenomenon, and its achievement a fundamentally social and collaborative process. Within this perspective, knowledge and meaning are co-constructed as joint 


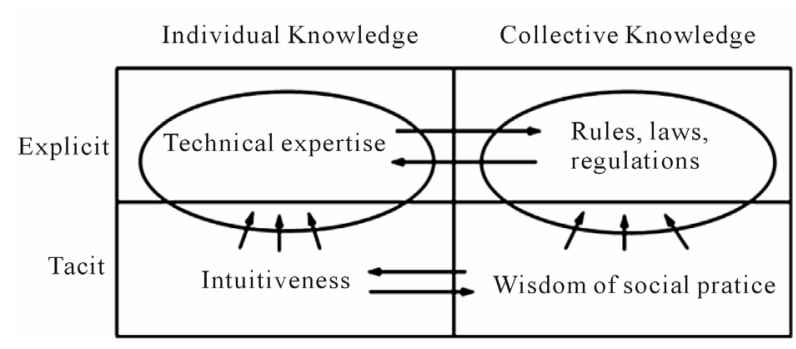

Figure 2.

Baumard's model with four types of knowledge. Notes on Baumard's model: Firstly, knowledge which is explicit and individual provides techniques that allow us to counter nets and traps. Secondly, through collective and explicit knowledge we achieve profound knowledge of a terrain, the environment, rules, and laws. Thirdly, knowledge which is tacit and collective is of the unspoken, invisible structure of a practice. Lastly, knowledge can be tacit and individual; where tacit expertise is complemented by "hard" technical knowledge - a sort of inimitable technical skills. These four forms of knowledge are indissociable.

interactional accomplishments. Learning is thus characterized as a process of participation and engagement in shared activities. This perspective also directs us to relate the interactional processes observed to particular institutional and cultural contexts in which the collaboration occurs. The implications are that educational success, and failure, may be explained partly by the quality of educational dialogues rather than just being the result of the intrinsic capability of individual students or the didactic presentational skills of individual teachers and/or the quality of the educational methods and materials being used (Rojas-Drummond et al., 2008).

\section{Relationship between Group Creativity and Knowledge Creation}

Creativity and knowledge are not opposed to each other, even though an overemphasis on current knowledge can sometimes smother creativity. On the contrary, creative thinking cannot happen unless the thinker already possesses knowledge of a certain reach and/or of a well-structured kind. However, the earlier studies on relationships between creativity and knowledge were discussed from cognitive or psychological perspectives (Weisberg, 1999). For example, Amabile (1989) summarizes her views on creativity in the context of a discussion of how to increase the chance of raising children who can think creatively. She presents the following as some the thinking styles that are often observed in creative adults and children: 1) breaking set, that is breaking out of your old patterns of thinking about something; 2) breaking out of scripts, which is much the same thing; and 3) perceiving freshly, that is, changing one's old ways.

Recent studies on group creativity have focused more on regarding individuals as a potential resource for group products than on considering individual cognitive processes. As Nijstad and Paulus (2003) emphasized, the knowledge of a collection of individuals is, in principle, larger than the knowledge of one individual, and the set of skills and abilities possessed by the group is larger than the set of skills and abilities possessed by an individual group member. One could therefore argue that groups have creative potential-because individual knowledge, skills, and abilities are combined, the group has the potential to be more creative than its separate members. However, a group's creative potential also depends on the level of diversity. As Moran and John-Steiner (2004) suggested, collaborators are not homogeneous people, but rather individuals with different perspectives, expertise, conceptualizations, working methods, temperaments, resources, needs, and talents. The interaction of these differences forms the foundation which enables the dynamic of collaboration to unfold. In addition, tacit knowledge in group innovation has been emphasized. Leonard and Sensiper (1998) pointed out that one form of collective tacit knowledge encompasses the entire production system, allowing individuals to contribute to innovation without explicit communication because they understand at a systemic level how all the individual operations in an organization fit together.

However, any new idea can be a potential start for learning new knowledge. Thus, creativity is an inspirational force that generates new ideas or produces novel combinations of existing ideas, leading to further solutions or a deeper understanding (Pahl et al., 2007). As Craft (2005) emphasizes, we can see creativity as, effectively, offering students opportunities to shape new knowledge. In this sense, group creativity could be viewed as a driver of the spiral of knowledge creation models. In other words, knowledge creation does not start from scratch but is a process of transforming and developing - sometimes in a radical way - existing ideas and practices (Paavola, Lipponen, \& Hakkarainen, 2004). Creative ideas motivate and direct the transforming process, since any learning activities seek the pursuit of newness. As Bereiter and Scardamalia (1993) suggested, creative expertise is the continuous effort of going beyond the current level of accomplishment and working at the edge of one's competence to adapt to the progressively changing requirements of the environment. So in groups, creativity and learning are closely related. It is impossible to distinguish between the processes of participation, interaction and response, and creative activity and learning (O’Hear \& Sefton-Green, 2004).

\section{Empirical Methods for Studying Group Creativity}

According to Grossen (2008), about 30 years ago when pioneering scholars began to study the role of peer collaboration in development and learning, they were quite confident that they would be able to identify the conditions which promote efficient collaboration and that, once these conditions had been identified, collaborative work could be transferred into the classroom. Unfortunately, it soon appeared that the conditions which enable collaboration to be effective were much more complex than expected, and were related to a number of dimensions such as interpersonal relationships, the characteristics of the task, the quality of talk, social and institutional contexts, the students' definition of the situation and task, and so on. Hence, researchers found that their empirical methods needed to be diversified in order to achieve a comprehensive view of peer collaboration in context. Both quantitative and qualitative views coexist in group creativity studies, and these are described in the following.

\section{Quantitative Approaches to Group Creativity}

The quantitative view is that creativity can be said to consist of one or more factors which people may possess in varying amounts. The quantitative view is a basic tenet of the research 
that uses psychometric tests of creativity (Goncalo \& Staw, 2006). As Punch (2009) said, the early social scientists, especially those in psychology and sociology, were impressed by the progress of the natural sciences, especially the method of building knowledge. They saw the core of the scientific method as two things - the experiment and measurement. Thus, in the most general terms, quantitative research does three main things: 1) it conceptualizes reality in terms of variables; 2) it measures these variables; and 3) it studies relationships between these variables. Thus variables are central concepts in quantitative research. Two main strands have been developed within the fields of quantitative design and data analysis (Punch, 2009):

- The comparison-between-groups strand, based on the experiment, and with the t-test and analysis of variance as its main statistical feature.

- The relationships-between-variables strand (correlational survey), based on non-experimental reasoning, with correlation and regression as its main features.

The two strands have been used in group creativity research. For example, efforts to use the first strand have been made by researchers such as Goncalo and Staw (2006), Kurtzberg (2005), Choi and Thompson (2005), and Jung (2001). According to Mayer (1999), three important characteristics of the experimental approach are 1) controlled environments, in which researchers present creativity problems to people in artificial contexts; 2) quantitative measurement, in which researchers make quantitative measurements; and 3) cognitive task analysis, in which researchers analyze the component processes involved in creative-thinking tasks. Although the experimental approaches reduce the complexity surrounding creativity and thereby allow sound inferences to be made about causality, they may lack results that can be generalized to explain real creative thinking. This is because creativity may depend on spontaneity, which is contrary to control.

In contrast, the second strand focuses on large-scale studies in a given organizational, social, or cultural environment. Studies based on this strand have been carried out such as those of Bain et al. (2001), Pirola-Merlo and Mann (1962), and Fiedler (2004). A series of models or tools for measuring creativity have been developed, for example, specific instruments for assessing climate or impact of environment on creativity, such as the Working Environment Inventory (WEI) (Amabile \& Gryskiewicz, 1989) and Creative Climate Questionnaire (CCQ) (Ekvall, 1987). Studies of this strand have deepened the understanding of group creativity as a complex phenomenon because of the many influencing factors on group creativity and their relationships. However, both strands emphasize the precise measurement of creativity for research purposes in artificially contrived settings, which demonstrates the limitation of quantitative research.

\section{Qualitative Approaches to Group Creativity}

In contrast, the qualitative view focuses on the life stories of creative people and, unlike quantitative research, most research can be naturalistic in terms of studying people in their natural settings. As Craft (2005) pointed out, since the 1990s, the methodology for investigating creativity has shifted from large-scale studies which aim to measure creativity, toward ethnographic and qualitative approaches to research which focus on the actual sites of operation and practice, situating creativity in the specifics of the underlying disciplines, and in the social and cultural values and practices of the particular setting.

The main alternative paradigms within qualitative research include positivism, post-positivism, critical theory, and constructivism, but there are finer distinctions than these and more detailed subdivisions. From a qualitative view, research, like other things people do, is a human construction, framed and presented within a particular set of discourses (and sometimes ideologies), and conducted in a social context within certain sorts of social arrangements, which especially involve funding, cognitive authority, and power (Punch, 2009). Thus, peer collaboration is the core of studying group creativity. However, qualitative research is a complex, changing, and contested field - a site of multiple methodologies and research practices (Punch, 2009). Therefore, it is not a single entity, but an umbrella term that encompasses enormous variety. As Grossen (2008) suggested, researchers working on group creativity have employed various methods from different disciplines: naturalistic observations, field notes, ethnographic approaches, discourse analysis, questionnaires, interviews, and so on. Case studies help bring the hidden mental processes of well-known creative collaboration into the public realm through actions, dialogues, the use of tools, and studies of work in progress (Moran \& John-Steiner, 2004). The expanded set of methods is grounded in the researcher's ambition to capture group creativity as a comprehensive phenomenon (Grossen, 2008).

However, no single approach may be able to provide a complete theory of creativity. To some extent, the qualitative view of group creativity is too soft because it emphasizes qualitative descriptions of a few highly selected cases in authentic settings. Therefore, creativity research needs to be based on the creative use of research methodologies. As suggested by Mayer (1999), an important challenge for the next 50 years of creativity research is to develop a clearer definition of creativity and to use a combination of research methodologies that will move the field from speculation to specification. Although some efforts have been made to mix quantitative and qualitative methods, the newer combined approach has not yet had a major impact on the field, but it may provide a more comprehensive understanding of creative collaboration. Thus, group creativity research needs further exploration by combining diverse disciplines and methods.

\section{Conclusion}

In order to provide a framework for both the theoretical understanding and empirical studies of group creativity in a learning context, this paper has reviewed literature focusing on 1) creativity theory development from individual to group level; 2) understanding group creativity and knowledge creation, and their relationship within a social-cultural framework; and 3) the methodology of group creativity study. The new insights provided by sociology research are driving creativity theory to broaden the scope and levels of its research. The current group creativity research focuses mainly on three aspects: group creativity in context, group-level creative synergy, and strategies for developing group creativity. Knowledge creation is a social process that involves knowledge conversations between tacit knowledge and explicit knowledge, and between individual knowledge and group knowledge. Group creativity can viewed as the driver of knowledge creation; however, individual knowledge is the potential resource to develop group creativity. 
These points lead to a series of questions that it would be valuable to explore further such as the following: What factors influence individual creative contributions at the group level in a specific learning environment? What environmental factors influence group-level creative synergy? From a knowledgecreation view of group creativity, what elements are necessary for building a learning environment conducive to creativity? As the literature suggests, both quantitative and qualitative approaches that include a diversity of methods can be employed to answer these questions-which calls for a mix of methods to be used in future studies.

\section{REFERENCES}

Amabile, T. M. (1996). Creativity in context: Update to the social psychology of creativity. Boulder, CO: Westview Press.

Amabile, T. M., \& Gryskiewicz, N. D. (1989). The creativity environment scales: Working environment inventory. Creativity Research Journal, 2, 231-253. doi:10.1080/10400418909534321

Aschenbrenner, J., \& Hellwig, M. (2009). Socio-cultural perspectives: The influence of our social environment on development. URL (last checked 4 June 2012).

http://workbloglearning.wordpress.com/2009/04/01/socio-cultural-pe rspectives-the-influence-of-our-social-environment-on-development/

Baumard, P. (1999). Tacit knowledge in organizations. London: Sage Publications.

Beghetto, R., \& Kaufman, J. (2007). Toward a broader conception of creativity: A case for "mini-c" creativity. Psychology of Aesthetics, Creativity, and the Arts, 1, 73-79. doi:10.1037/1931-3896.1.2.73

Bereiter, C., \& Scardamalia, M. (1993). Surpassing ourselves: An inquiry into the nature and implications of expertise. Chicago, IL: Open Court.

Borghini, S. (2005). Organizational creativity: Breaking equilibrium and order to innovate. Journal of Knowledge Management, 9, 19-33. doi:10.1108/13673270510610305

Choi, H. S., \& Thompson, L. (2005). Old wine in a new bottle: Impact of membership change of group creativity. Organizational Behavior and Human Decision Processes, 98, 121-132. doi:10.1016/j.obhdp.2005.06.003

Cole, M. (2005). Culture in development. In M. H. Bornstein, \& M. E. Lamb (Eds.), Developmental science: An advanced textbook (5th ed.). Mawah, NJ: Lawrence Erlbaum Associates.

Corsi, P., Richir, S., Chiristofol, H., \& Samier, H. (2006) Innovation engineering: The power of intangible networks. London: ISTE Ltd.

Craft, A. (2005). Creativity in schools: Tensions and dilemmas. New York: Routledge. doi:10.4324/9780203357965

Craft, A., Jeffrey, B, \& Leibling, M. (2001). Creativity in education. London: Continuum International Publishing Group.

De Laat, M., \& Lally, V. (2004). Creativity and the net: How do researchers collaborate creatively using the internet? In D. Miell, \& K. Littleton (Eds.), Collaborative creativity, contemporary perspectives (pp. 126-143). London: Free Associate Books.

Dreyfus, H., \& Dreyfus, S. (1986). Mind over machine. New York: The Free Press.

Ekvall, G. (1987). The climate metaphor in organization theory. In B. M. Bass, \& P. J. D. Dretch (Eds.), Advances in organizational psychology: An international review. Thousand Oaks, CA: Sage.

European Commission (2008). Proposal for a decision of the European Parliament and of the Council Concerning the European Year of Creativity and Innovation (2009). Brussels: European Commission.

Fiedler, F. E. (1962). Leader attitudes, group climate, and group creativity. Journal of Abnormal and Social Psychology, 65, 308-318. doi:10.1037/h0048284

Goncalo, J. A., \& Staw, B. M. (2006). Individualism-collectivism and group creativity. Organizational Behavior and Human Decision Processes, 100, 96-100. doi:10.1016/j.obhdp.2005.11.003

Grossen, M. (2008). Methods for studying collaborative creativity: An original and adventurous blend. Thinking Skills and Creativity, 3, 246-249. doi:10.1016/j.tsc.2008.09.005
Guilford, J. P. (1950). Creativity. American Psychologist, 5, 444-454. doi:10.1037/h0063487

Jeffrey, B., \& Craft, A. (2001). The universalization of creativity. In A. Craft, B. Jeffrey, \& M. Leibling (Eds.), Creativity in education (pp. 1-13). London: Continuum International Publishing Group.

Jung, D. I. (2001). Transformational and transactional leadership and their effects on creativity in groups. Creativity Research Journal, 13, 185-195. doi:10.1207/S15326934CRJ1302_6

Koskinen, K. U., Pihlanto, P., \& Vanharanta, H. (2003). Tacit knowledge acquisition and sharing in a project work context. International Journal of Project Management, 21, 281-290. doi:10.1016/S0263-7863(02)00030-3

Kurtzberg, T. R. (2005). Feeling creative, being creative: An empirical study of diversity and creativity in teams. Creativity Research Journal, 17, 51-65. doi:10.1207/s15326934crj1701_5

Kurtzberg, T. R., \& Amabile, T. M. (2000-2001). From Guilford to creative synergy: Opening the black box of team-level creativity. Creativity Research Journal, 13, 285-294. doi:10.1207/S15326934CRJ1334_06

Leon, P. G. B., Mann, L., \& Pirola-Merlo, A. (2001). The innovation imperative: The relationships between team climate, innovation, and performance in research and development teams. Organisational Behavior, 32, 55-73.

Leonard, D., \& Sensiper, S. (1998). The role of tacit knowledge in group innovation. California Management Review, 40, 112-132.

Leonard-Barton, D., \& Swap, W. C. (1999). When sparks fly: Igniting creativity in groups. Boston, MA: Harvard Business Press.

Levine, J. M., \& Moreland, R. L. (2004). Collaboration: The social context of theory development. Personality and Social Psychology Review, 8, 164-172. doi:10.1207/s15327957pspr0802_10

Littleton, K., Rojas-Drummond, S., \& Miell, D. (2008). Introduction to the special issue: "Collaborative creativity: Socio-cultural perspectives". Thinking Skills and Creativity, 3, 175-176. doi:10.1016/j.tsc.2008.09.004

Lohman, M. C., \& Finkelstein, M. (2000). Designing groups in problem-based learning to promote problem-solving skill and self-directedness. Instructional Science, 28, 291-307. doi:10.1023/A:1003927228005

Mayer, R. E. (1999). Fifty years of creativity research. In R. J. Sternberg (Eds.), Handbook of creativity (pp. 449-460). New York: Cambridge University Press.

Miell, D., \& Littleton, K. (2004), Collaborative creativity, contemporary perspectives. London: Free Associate Books.

Moran, S., \& John-Steiner, V. (2004). How collaboration in creative work impacts identity and motivation. In D. Miell, \& K. Littleton (Eds.), Collaborative creativity, contemporary perspectives (pp. 1125). London: Free Associate Books.

Newman, M. J. (2005). Problem based learning: An introduction and overview of the key features of the approach. Journal of Veterinary, 32, $12-20$.

Nielsen, K. (2002). The concept of tacit knowledge-A critique. Outlines, 2, 3-17.

Nijstad, B. A., \& Paulus, P. B. (2003). Group creativity: Common themes and future directions. In P. B. Paulus (Ed.), Group creativity: Innovation through collaboration (pp. 326-346). New York: Oxford University Press.

Nonaka, I. (1991). The knowledge-creating company. Harvard Business Review, Novermber-December, 96-104.

Nonaka, I., \& Takeuchi, H. (1995). The knowledge-creating company: How Japanese companies create the dynamic of innovation. New York: Oxford University Press

Nonaka, I., \& Toyama, R. (2003). The knowledge-creating theory revisited: Knowledge creation as a synthesizing process. Knowledge Management Research \& Practice, 1, 2-10. doi:10.1057/palgrave.kmrp.8500001

O’Hear, S., \& Sefton-Green, J. (2004). Creative “communities”: How technology mediates social worlds. In D. Miell, \& K. Littleton (Eds.), Collaborative creativity, contemporary perspectives (pp. 113-125). London: Free Associate Books.

Paavola, S., Lipponen, L., \& Hakkarainen, K. (2004). Models of innovative knowledge communities and three metaphors of learning. Re- 
view of Educational Research, 74, 557-576. doi:10.3102/00346543074004557

Pahl, G., Beitz, W., Feldhusen, J., \& Grote, K. H. (2007). Engineering design: A systematic approach (3rd ed.). London: Springer.

Paulus, P. B. (2000). Groups, teams, and creativity: The creative potential of idea-generating groups. Applied Psychology: An International Review, 49, 237-262. doi:10.1111/1464-0597.00013

Paulus, P. B. (2003).Group creativity: Innovation through collaboration. New York: Oxford University Press.

Polanyi, M. (1994). Personal knowledge. London: Routledge and Kegan Paul.

Punch, K. F. (2009). Introduction to research methods in education. London: Sage Publications.

Resnick, L. B. (1991). Shared cognition: Thinking as social practice. In L. B. Resnick, J. M. Levine, \& S. D. Teasley (Eds.), Perspectives on socially shared cognition (pp. 1-20). Washington DC: American Psychological Association. doi:10.1037/10096-018

Robinson, A. G., \& Stern, S. (1997). Corporative creativity: How innovation and improvement actually happen. San Francisco, CA: Berrett-Koehler Publishers.

Rojas-Drummond, S. M., Albarrán, C. D., \& Littleton, K. S. (2008). Collaboration, creativity and the co-construction of oral and written texts. Thinking Skills and Creativity, 3, 177-191.

doi:10.1016/j.tsc.2008.09.008

Rosenberg, N. (1982). Inside the black box: Technology and economics. Cambridge: Cambridge University Press.

Ryhammar, L., \& Brolin, C. (1999). Creativity research: Historical considerations and main lines of development. Scandinavian Journal of Educational Research, 43, 259-273. doi:10.1080/0031383990430303

Sawyer, R. K. (2006). Explaining creativity: The science of human innovation. New York: Oxford University Press.

Sawyer, R. K. (2007). Group genius: The creative power of collaboration. New York: Basic Books.

Sawyer, R. K. et al. (2003). Creativity and development. Cary, NC: Oxford University Press.
Smith, E. A. (2001). The role of tacit and explicit knowledge in the workplace. Journal of Knowledge Management, 5, 311-321. doi:10.1108/13673270110411733

Sonnenburg, S. (2004). Creativity in communication: A theoretical framework for collaborative product creation. Creativity and Innovation Management, 13, 254-262. doi:10.1111/j.0963-1690.2004.00314.X

Sternberg, R. J., \& Lubart, T. I. (1999). The concept of creativity: Prospects and paradigms. In R. J. Sternberg (Ed.), Handbook of creativity (pp. 3-15). New York: Cambridge University Press.

Strijbos, J. W., \& Martens, R. L. (2001). Group-based learning: Dynamic interaction in groups. Proceedings of EURO-CSCL Conference 2001, Maastricht, 22-24 March 2011, 569-576.

Thompson, L., \& Brajkovich, L. F. (2003). Improving the creativity of organizational work groups. The Academy of Management Executive, 17, 96-111. doi:10.5465/AME.2003.9474814

Tylor, E. B. (1889). Primitive culture: Researches into the development of mythology, philosophy, religion, language, art, and custom. New York: Holt (Original work published 1871).

Villalba, E. (2008). On creativity: Towards an understanding of creativity and its measurements. Brussels: European Commission.

Wagner, R. K., \& Sternberg, R. L. (1986). Tacit knowledge and intelligence in the everyday world. In R. J. Sternberg, \& R. K. Wagner (Eds.), Practical intelligence: Nature and origins of competence in the everyday world (pp. 51-84). Cambridge: Cambridge University Press.

Weber, M. (1922). Die protestantische ethik und der geist des kapitalismus. URL (last checked 1 June 2012). http://www.s-hb.de/ klaus.boenkost/pdf-docs/Weber-Protestantische-E thik.pdf

Weisberg, R. W. (1999). Creativity and knowledge: A challenge to theories. In R. J. Sternberg (Ed.), Handbook of creativity (pp. 226248). New York: Cambridge University Press.

Woodman, R. W., Sawyer, J. S., \& Griffin, R. W. (1993). Toward a theory of organizational creativity. Academy of Management Review, 18, 293-321. doi:10.5465/AMR.1993.3997517 